\title{
Effectiveness of high-intensity interval training on the mental and physical health of people with chronic schizophrenia
}

This article was published in the following Dove Press journal:

Neuropsychiatric Disease and Treatment

25 May 2015

Number of times this article has been viewed

\author{
Meng Hsiu Wu ${ }^{1,2}$ \\ Chin Pang Lee ${ }^{1-3}$ \\ Shih Chieh Hsu ${ }^{1,3}$ \\ Chia Ming Changl,3 \\ Ching Yen Chen ${ }^{1-3}$ \\ 'Department of Psychiatry, Chang \\ Gung Memorial Hospital, Linkou, \\ Taiwan; ${ }^{2}$ Men's Health Center, Chang \\ Gung Memorial Hospital, Linkou, \\ Taiwan; ${ }^{3}$ School of Medicine, Chang \\ Gung University, Taoyuan, Taiwan
}

Background: Low-volume high-intensity interval training (HIIT) is emerging as a time-efficient exercise strategy for improving cardiorespiratory fitness and for controlling blood sugar levels and hypertension. In addition, patient acceptance of HIIT may improve adherence to exercise programs. This study evaluated the effectiveness of HIIT for improving the mental and physical health of people with chronic schizophrenia.

Methods: Twenty patients attending a psychiatric day care unit volunteered for an 8-week program of HIIT. Blood pressure, resting heart rate, body weight, body mass index, waist and hip circumference, and waist-to-hip ratio were measured weekly. The Positive and Negative Syndrome Scale score was recorded at baseline and at the end of the study. Beck Depression Inventory (BDI) and Beck Anxiety Inventory (BAI) scores were recorded every 2 weeks.

Results: Statistically significant changes occurred in the physical and mental parameters measured in the 18 patients who completed the study. Body weight, body mass index, resting heart rate, and pulse pressure decreased significantly. Mean arterial pressure and diastolic blood pressure increased significantly. Mental health scores improved, with the Negative Scale score decreasing from $31.17 \pm 5.95$ to $27.78 \pm 3.57(P<0.01)$ and the General Psychopathology Scale score from $14.28 \pm 2.16$ to $13.00 \pm 1.72(P<0.01)$. Positive Scale scores changed, but not significantly, from $12.28 \pm 2.27$ to $12.33 \pm 2.00(P=0.729)$. Scores on the BDI (from 19.56 \pm 15.28 to $15.89 \pm 14.33, P<0.001$ ) and BAI (from $13.67 \pm 13.83$ to $10.06 \pm 11.18, P=0.003$ ) both improved significantly.

Conclusion: This study demonstrated that HIIT has positive effects on the physical and mental health of patients with chronic schizophrenia.

Keywords: schizophrenia, exercise, depression, anxiety, body weight, blood pressure

\section{Introduction}

There is increasing interest in the role physical exercise plays in enhancing physical and mental health. Most research thus far has shown that exercise used as adjuvant therapy for psychiatric patients can improve their mental health and cardiovascular fitness. ${ }^{1,2}$ It has also been shown that exercise can reduce the level of care needed for patients with schizophrenia. ${ }^{2}$ A systematic review indicated volume expansion in the hippocampus in schizophrenia patients after physical exercise. ${ }^{3}$

Although the results of most studies have pointed to the positive effects of exercise among psychiatric patients, getting patients to adhere to an exercise program is still a very real challenge. This is particularly true among psychiatric patients. Reasons for this include poor motivation, negative symptoms, and complaints that exercise is too time-consuming. ${ }^{4-6}$ A systematic review and meta-analysis demonstrated that sedentary behavior of outpatients with schizophrenia appears higher than that of their
Correspondence: Ching-Yen Chen Department of Psychiatry, Chang Gung Memorial Hospital, Linkou, 5, Fu-Shin Street, Kweishan 333, Taoyuan, Taiwan Tel $+8863328 \quad 1200$ extension 2439 Fax +886 33280267

Email psycychen@yahoo.com.tw
Neuropsychiatric Disease and Treatment 2015:II 1255-1263 
healthy peers. ${ }^{7}$ A study focused on the barriers to physical activity among people with schizophrenia indicated the most frequently ones were patients' lack of motivation ( $45 \%$ of respondents) and lack of priority given to physical activity by other health care professionals $(28 \%)^{8,9}$

Low-volume high-intensity interval training (HIIT) is emerging as a time-efficient exercise strategy for improving health and fitness among the general population. Researchers suggest that, compared with lower-intensity continuous endurance training, HIIT leads to better oxygen uptake, greater muscle deoxygenation, and better exercise performance. ${ }^{10,11}$ HIIT has proved effective for improving cardiorespiratory fitness, blood sugar control, body fat loss, and hypertension control. ${ }^{12-17}$

Another study also demonstrated that patients participating in high-intensity interval running had higher perceived enjoyment after exercise compared with measurements made after moderate-intensity continuous running. This implied that HIIT improved exercise adherence. ${ }^{18}$

On the other side, some researchers noted that interval training has potential physical risks and also a negative psychological effect, evoking an avoidant response and withdrawal. HIIT also required participants' self-discipline and self-regulation to reach the high-intensity level required. ${ }^{19}$

HIIT programs are designed according to the ratio of work to rest duration (W:R ratios). The "work" period involves short-duration, full-effort exercise that boosts the heart rate (HR) to $85 \%-95 \%$ maximal HR. W:R ratios are tailored to the level of fitness and physical condition of individual groups. For example, for athletic training, a 2:1 or 1:1 W:R ratio produces favorable results. For less fit groups, a $\mathrm{W}: \mathrm{R}$ ratio of $1: 3$ or $1: 4$ would be more appropriate..$^{20,21}$

Several studies have focused on the results of interval training in patients with schizophrenia. One pilot study showed that a 14-week aerobic interval training program for patients with first-episode psychosis improved metabolic outcomes (waist circumference [WC] WC $-4.3 \mathrm{~cm}$, $P=0.015$ ) and cardiorespiratory fitness (resting HR -8.6 beats per minute; $P<0.05)$, and increased maximal oxygen uptake $\left(\mathrm{VO}_{2}\right.$ max $)$ by $38 \%(P<0.001)$ over a relatively short period. ${ }^{22} \mathrm{~A}$ controlled trial showed that 8 weeks of high aerobic intensity training improved peak oxygen uptake ( $\mathrm{VO}_{2}$ peak), and net mechanical efficiency of walking. However, psychiatric symptoms did not improve correspondingly, as shown by results on the Positive and Negative Syndrome Scale (PANSS) and Calgary Depression Scale for Schizophrenia. ${ }^{23}$
A later study by the same group showed that single sessions of high aerobic HIIT reduced distress and anxiety among patients with depression or schizophrenia within 15 minutes after exercise and at 3 hours. ${ }^{24} \mathrm{~A}$ case report also shows interval training was far more effective than moderate continuous training for reducing resting HR, increasing HR variability, and improving the ventilatory threshold, or the point at which respiration becomes labored. ${ }^{25}$

A review literature indicates that exercise is a useful adjunct treatment for some of the negative symptoms of schizophrenia, in addition to depression and anxiety. Additionally, exercise acts as a coping strategy for positive symptoms, such as auditory hallucinations. ${ }^{26}$

Although most studies demonstrated that exercise had positive benefits for people with schizophrenia, the training programs used are variable. A systematic literature review suggested that an exercise program lasting 30-40 minutes per session and undertaken three times weekly at moderate intensity is valuable for people with schizophrenia. ${ }^{27}$

In this study, we designed a shorter duration but higher intensity exercise program to determine the complete rate of the participants and positive or negative outcomes for physical and mental health in patients with chronic schizophrenia.

\section{Materials and methods Test setting and participants}

All participants in this study were psychiatric patients receiving outpatient day care treatment at Chang Gung Memorial Hospital. The inclusion criteria were: outpatient day care treatment and a diagnosis of schizophrenia according to the DSM-5 (Diagnostic and Statistical Manual of Mental Disorders, Fifth Edition). Exclusion criteria were: hypertension, or diabetes mellitus without control; history of brain injury, epilepsy, myocardial infarction, or recent musculoskeletal disease; using medication that affects HR (eg, beta-blockers, asthma medications, stimulants, dioxin, antiarrhythmic agents). The study was approved by the Chang Gung Memorial Hospital ethics and scientific committee (102-4619B), and written informed consent was obtained from all subjects.

We recruited an initial group of 28 patients, of whom 20 were included in the study. Eighteen patients completed the training. Two participants were withdrawn after their HR did not reach the goal required for participation in HIIT (Figure 1). Demographic data for the group are shown in Table 1.

\section{Study design and methods}

This was a prospective study, in which an 8-week training program was offered to all participants. Each session in the 


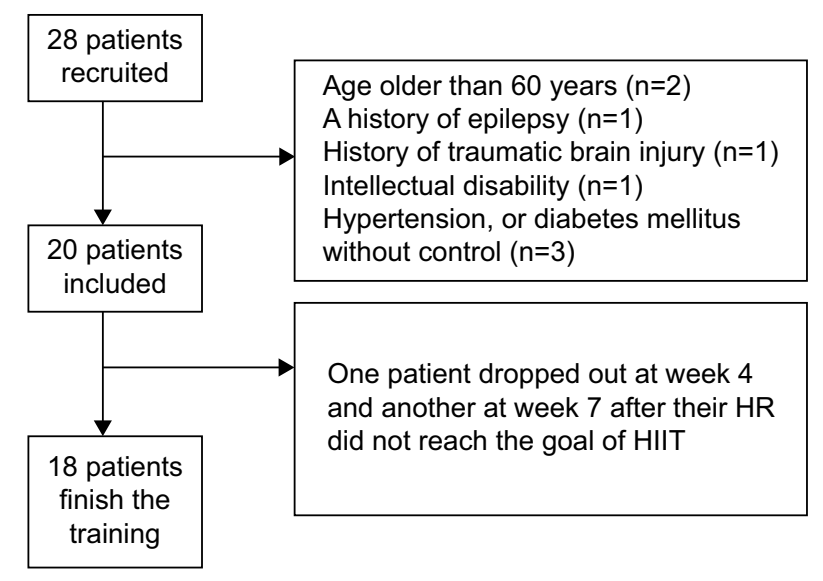

Figure I Flow of participants in each stage of the trial.

Notes: Of the original 28 patients recruited, 20 were included in the final study group. Eight patients were excluded due to their physical condition. Two patients dropped out during training because their heart rates did not reach the goal needed for participation in HIIT.

Abbreviations: HIIT, high-intensity interval training; HR, heart rate.

HIIT training program was 25 minutes in duration. The sessions included a 5-minute warm-up period, followed by a 15-minute course of HIIT, and then a 5-minute period of stretching (Figure 2). The training programs were designed with bodyweight exercises that did not require the use of equipment.

All participants trained in groups at the same place and at the same time, 3 days a week, for 8 weeks. During the training program, participants wore an HR monitor watch (FT60; Polar Electro Inc, Lake Success, NY, USA) to evaluate the intensity of training. The recorded HR data was uploaded to a computer and checked by two investigators. If the peak HR during the work period was below 95\% of maximum HR, participants could not continue in the study. The maximum HR was calculated according to the age-based formula, ie, 220 minus participant age = estimated maximum HR. The general medical condition of the participants was supervised by a specialist in internal medicine during the training program.

\section{Data collection and measures}

For the physical health outcomes survey, we focused on the patients' blood pressure (BP), resting HR, body weight (BW), body mass index (BMI), WC, hip circumference (HC), and the waist to hip ratio. In addition to systolic and diastolic BP, we measured and analyzed mean arterial pressure (MAP) and pulse pressure (PP). The physical data were recorded in the resting state at baseline, each week, and at the end of training. The measurement was checked by two investigators according to WHO STEPwise approach to surveillance protocol.

To evaluate the patients' mental health outcomes, a trained psychiatrist interviewed each patient using the PANSS at the beginning of the study and at the end of training. In addition, patients used two self-report questionnaires, ie, the Beck Depression Inventory (BDI) and the Beck Anxiety Inventory (BAI), on the first day and every 2 weeks thereafter until the end of the study.

\section{Statistical analysis}

The statistical analysis was performed using Statistical Package for the Social Sciences version 17 software (SPSS Inc, Chicago, IL, USA). Normality was tested using Kolmogorov-Smirnov tests. Changes in the physical data, including $\mathrm{BW}, \mathrm{BMI}, \mathrm{WC}, \mathrm{HC}$, waist to hip ratio, $\mathrm{BP}$, and resting HR (parametric), were analyzed by repeated-measures one-way analysis of variance (time effect). Changes in mental health outcomes, including BDI and BAI, were analyzed by Friedman's analysis of variance. The PANSS data (nonparametric) were analyzed by the Wilcoxon matched-pairs signed-rank test. $P<0.05$ was considered to be

Table I Demographic data*

\begin{tabular}{|c|c|c|c|c|}
\hline & Participants (n) & Age (years) & $\begin{array}{l}\text { Onset age of schizophrenia } \\
\text { (years) }\end{array}$ & $\begin{array}{l}\text { Duration of schizophrenia } \\
\text { (years) }\end{array}$ \\
\hline All participants & & $38.39 \pm 8.24(25-55)$ & $21.39 \pm 6.8(12-43)$ & $15.39 \pm 7.3(5-12)$ \\
\hline \multicolumn{5}{|l|}{ Sex } \\
\hline Male & 8 & $39.63 \pm 10.2(22-55)$ & $24.63 \pm 8.0(16-43)$ & $12.38 \pm 6.2(5-25)$ \\
\hline Female & 10 & $37.40 \pm 6.1(27-48)$ & $18.80 \pm 4.1(12-26)$ & $17.80 \pm 7.2(8-30)$ \\
\hline \multicolumn{5}{|l|}{ Marital status } \\
\hline Married & 2 & $51.50 \pm 3.5(48-55)$ & $35.50 \pm 7.5(28-43)$ & $8.50 \pm 3.5(5-12)$ \\
\hline Unmarried & 16 & $36.75 \pm 7.1(25-48)$ & $19.63 \pm 4.12(12-28)$ & $16.25 \pm 7.2(7-30)$ \\
\hline \multicolumn{5}{|c|}{ Educational level } \\
\hline$\leq 12$ years & 17 & $37.82 \pm 8.1(25-55)$ & $21.29 \pm 7.0(12-43)$ & $|4.82 \pm 7|.(5-30)$ \\
\hline$\geq 13$ years & 1 & 48 & 23 & 25 \\
\hline
\end{tabular}

Note: *Data are reported as the mean \pm standard deviation (minimum-maximum). 


\section{The study design for HIIT training}

Start: 5 minutes warm up

HIIT program

Every circuit takes 3 minutes, 45 seconds

$\begin{array}{ll}\rightarrow \text { Work } & 15 \text { seconds } \\ \rightarrow \text { Rest } & 10 \text { seconds } \\ \rightarrow \text { Work } & 15 \text { seconds } \\ \rightarrow \text { Rest } & 20 \text { seconds } \\ \rightarrow \text { Work } & 15 \text { seconds } \\ \rightarrow \text { Rest } & 30 \text { seconds } \\ \rightarrow \text { Work } & 15 \text { seconds } \\ \rightarrow \text { Rest } & 40 \text { seconds } \\ \rightarrow \text { Work } & 15 \text { seconds } \\ \rightarrow \text { Rest } & 50 \text { seconds }\end{array}$

Repeat four circuits

End: 5 minutes of stretches

Figure 2 Design of the HIIT program.

Notes: "Work" period indicates short-duration, full-effort exercise, to boost heart rate to $85 \%-95 \%$, or to maximal heart rate.

Abbreviation: HIIT, high-intensity interval training.

statistically significant. The data are reported as the mean \pm standard deviation.

\section{Results}

\section{Improvements in physical health outcomes}

Changes in the physical data are shown in Table 2 and Figure $3 \mathrm{~A}-\mathrm{C}$. There was a significant decrease in mean $\mathrm{BW}$, BMI, resting HR, and PP. MAP and diastolic BP increased significantly. Mean BW and BMI decreased, mainly in week 8 and at the end of training (Figure 3A). Mean WC decreased, but not significantly, from $92.6 \pm 10.8 \mathrm{~cm}$ at baseline to $92.0 \pm 11.1$ $\mathrm{cm}$ at the end of training (analysis of variance, time effect, $P=0.303$ ). While the mean WC decreased in weeks 2 and 3 of the study, this rebounded in weeks 4 and 5. The mean WC change was not significant at the end of the study (Figure 3A). Similarly, mean HC decreased, but not significantly, from a baseline of $101.8 \pm 6.3 \mathrm{~cm}$ to $101.3 \pm 7.6 \mathrm{~cm}$ at the end of training $(P=0.243)$. The mean waist to hip ratio also changed, but not significantly, from a baseline of $0.908 \pm 0.08$ to $0.906 \pm 0.06$ at the final examination $(P=0.303$, Figure $3 C)$.

\section{Improvement in negative symptoms, depression, and anxiety}

PANSS, BDI, and BAI scores were all significantly decreased (Tables 3 and 4). By the end of the study, PANSS scores had decreased significantly, including the Total score $(P<0.001)$, Negative Scale score $(P<0.001)$, and General Psychopathology Scale score $(P=0.001)$. Several subscale scores in the Negative Scale decreased significantly, ie, poor rapport $(P=0.005)$, lack of spontaneity and flow of conversation $(P=0.014)$. Scores on several subscales included in the General Psychopathology Scale also decreased significantly: depression $(P=0.046)$, motor retardation $(P=0.020)$, uncooperativeness $(P=0.046)$, poor attention ( $P=0.046)$, disturbance of volition $(P=0.046)$, preoccupation $(P=0.046)$, and active social avoidance $(P=0.025)$. The total Positive Scale scores changed, but not significantly, from a mean of $12.28 \pm 2.27$ at baseline to $12.33 \pm 2.00$ at the end of the study $(P=0.729$; Table 3$)$.

BDI scores decreased significantly from a mean of $19.56 \pm 15.28$ at baseline to $15.89 \pm 14.33$ at the end of the study $(P<0.001)$. BAI scores also decreased significantly from a

Table 2 Physical measurements at baseline and at end of training

\begin{tabular}{|c|c|c|c|c|c|}
\hline \multirow[t]{2}{*}{ Physical items } & \multicolumn{2}{|c|}{ Baseline } & \multicolumn{2}{|c|}{ End of training } & \multirow{2}{*}{$\begin{array}{l}\text { P-value of ANOVA } \\
\text { time effect }\end{array}$} \\
\hline & Mean & SD & Mean & SD & \\
\hline Body weight (kg) & 75.17 & 13.8 & 73.72 & 14.3 & $0.022 *$ \\
\hline $\mathrm{BMI}\left(\mathrm{kg} / \mathrm{m}^{2}\right)$ & 27.76 & 4.2 & 27.21 & 4.3 & $0.022 *$ \\
\hline Waist circumference $(\mathrm{cm})$ & 92.58 & 10.8 & 92.00 & II.I & 0.303 \\
\hline Hip circumference $(\mathrm{cm})$ & 101.83 & 6.3 & 101.33 & 7.6 & 0.243 \\
\hline Waist to hip ratio & 0.9079 & 0.08 & 0.9059 & 0.06 & 0.309 \\
\hline Systolic BP (mmHg) & 128.92 & 11.7 & 125.00 & 11.6 & 0.065 \\
\hline Diastolic BP (mmHg) & 74.83 & 9.0 & 81.67 & 10.6 & $0.004 * *$ \\
\hline Pulse pressure $(\mathrm{mmHg})$ & 54.11 & 11.3 & 43.33 & 6.4 & $0.010 *$ \\
\hline Mean arterial pressure $(\mathrm{mmHg})$ & 92.86 & 8.5 & 96.11 & 10.5 & $0.015^{*}$ \\
\hline Resting heart rate (beats per minute) & 87.33 & 12.5 & 83.83 & 13.7 & $0.023 *$ \\
\hline
\end{tabular}

Notes: $* P<0.05 ; * * P<0.01$

Abbreviations: ANOVA, analysis of variance; BP, blood pressure; BMI, body mass index; SD, standard deviation. 
A

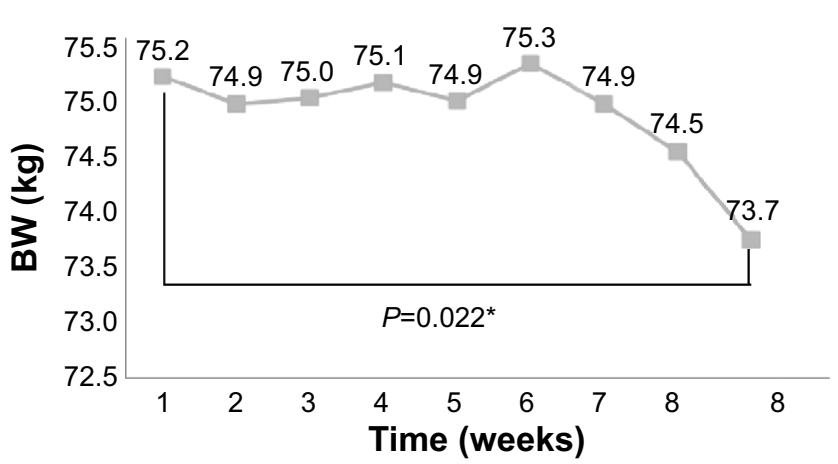

BMI

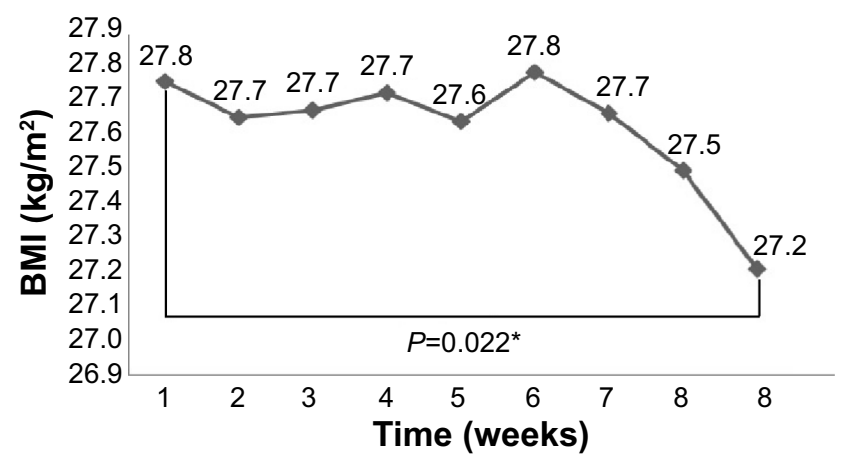

Resting HR

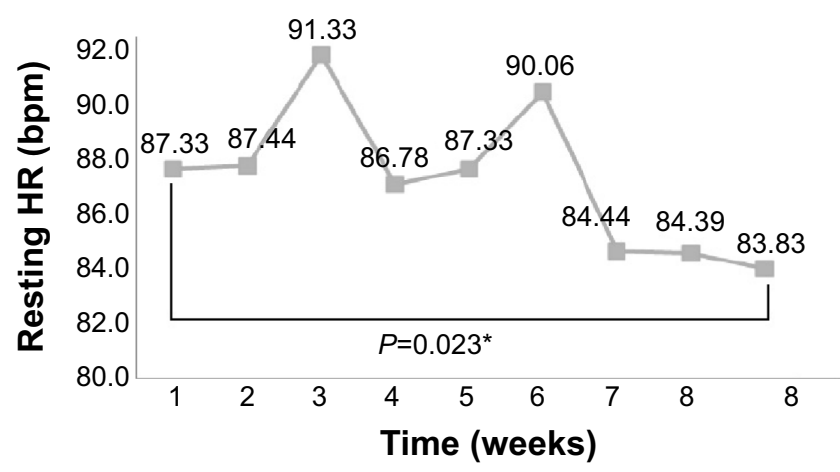

B

SBP

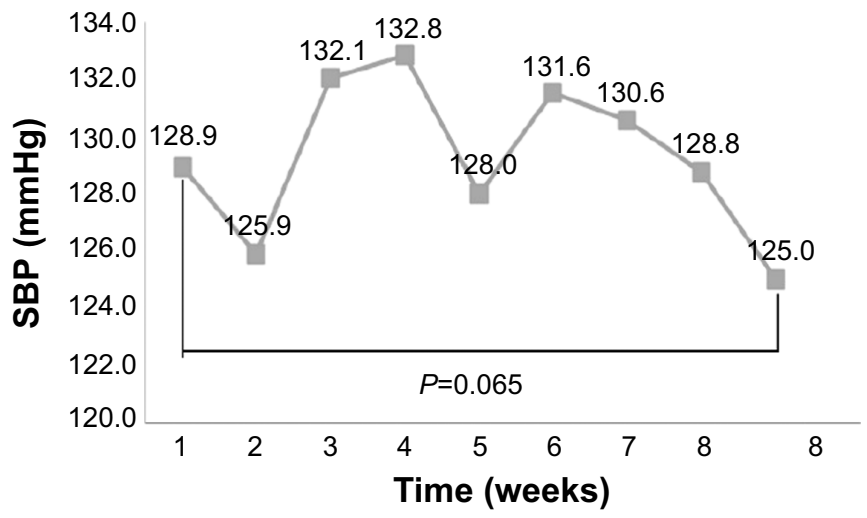

MAP

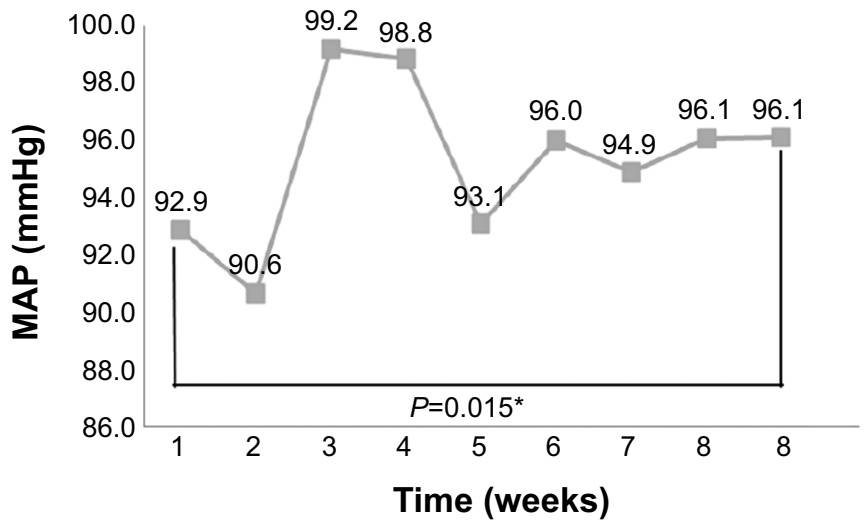

DBP

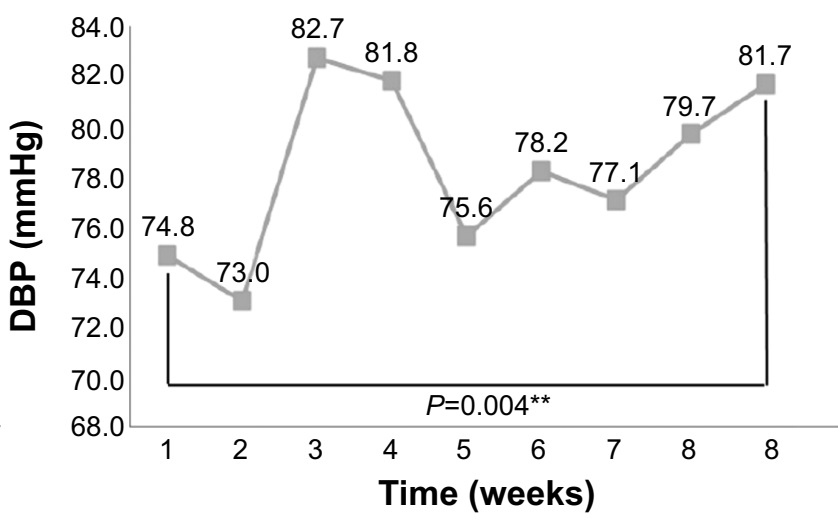

PP

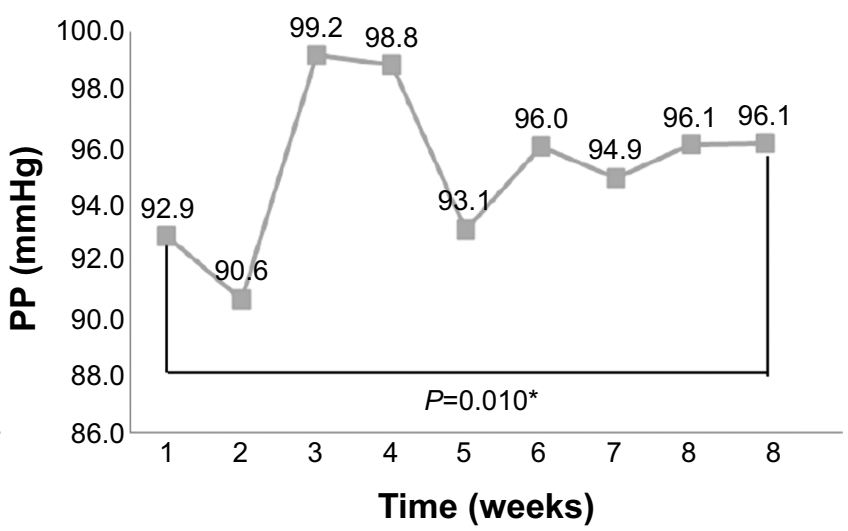

Figure 3 (Continued) 

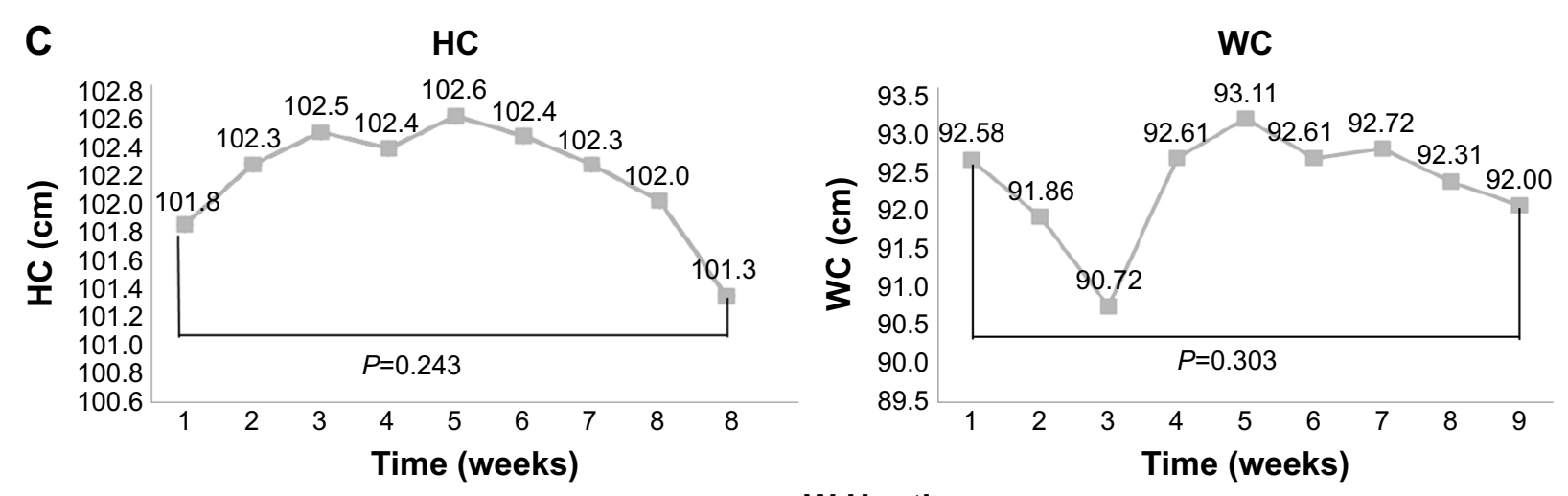

\section{W:H ratio}

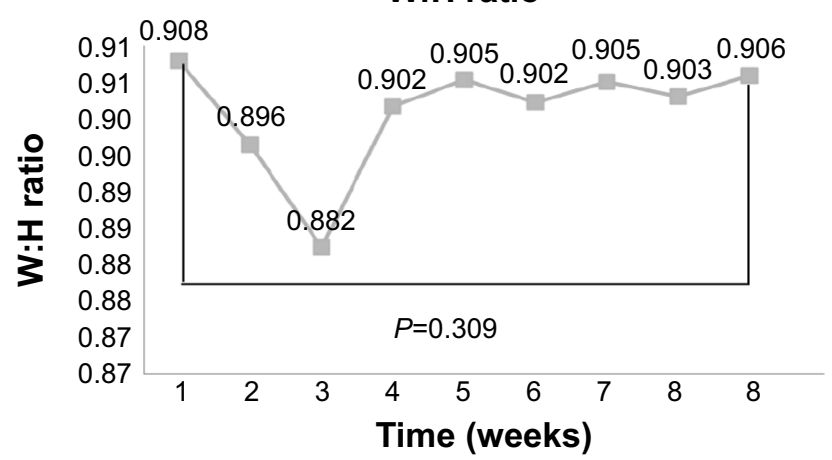

Figure 3 Change of physical measurements in each week.

Notes: (A) Changes in BW, BMI, and resting HR measured once a week. (*P<0.05; $* * P<0.01)$. (B) Changes in blood pressure (SBP, DBP, MAP, and PP) measured each week. ( ${ }^{*} P<0.05$; $\left.* * P<0.0 \mathrm{I}\right)$. (C) Changes in $\mathrm{WC}, \mathrm{HC}$, and $\mathrm{W}: \mathrm{H}$ ratio recorded every week.

Abbreviations: BMI, body mass index; BW, body weight; DBP, diastolic blood pressure; HC, hip circumference; HR, heart rate; MAP, mean arterial pressure; PP, pulse pressure; SBP, systolic blood pressure; WC, waist circumference; $\mathrm{W}: \mathrm{H}$, waist to hip.

mean of $13.67 \pm 13.83$ at baseline to $10.06 \pm 11.18(P=0.003)$ at the end of training (Table 4 and Figure 4).

\section{Discussion}

To date, only a few studies have evaluated the use of HIIT in patients with schizophrenia. This is the first study of the use of HIIT in patients with chronic schizophrenia, and the results show that HIIT can be successfully used in these patients. A previous pilot study by Abdel-Baki et al demonstrated that a 14-week aerobic interval training program conducted at a first-episode psychosis service $(\mathrm{n}=16)$ could improve patient $\mathrm{WC}(-4.3 \mathrm{~cm} ; P=0.015)$ and resting HR $(-8.6 \mathrm{bpm} ; P<0.05)$, and it also increased their $\mathrm{VO}_{2} \max$ by $38 \%$. The mean age of the subjects in that study was $25.9 \pm 3.9$ years. ${ }^{22}$ The mean age of the participants in our study was 38.39 \pm 8.24 (range: $25-55$ ) years, and the mean duration of their diagnosis of schizophrenia was 15.39 \pm 7.3 years. After an 8-week HIIT program, our subjects showed improved BW, BMI, resting HR, and PP, and decreases in negative symptoms, depression, and anxiety.

With regard to the effects of HIIT on BP, our participants' mean baseline data were systolic BP $128.92 \pm 11.7 \mathrm{mmHg}$ and diastolic BP $74.83 \pm 9.0 \mathrm{mmHg}$ (levels under the goal of systolic $\mathrm{BP}<140 \mathrm{mmHg}$ and diastolic $\mathrm{BP}<90 \mathrm{mmHg}$ recommended by the Eighth Joint National Committee) ${ }^{28}$
At the end of training, their average systolic BP was $125.00 \pm 11.6 \mathrm{mmHg}$ and the average diastolic BP was $81.67 \pm 10.6 \mathrm{mmHg}$, ie, still in the normal range.

To study the effects on BP further, we measured and analyzed MAP (MAP $=1 / 3$ systolic $\mathrm{BP}+2 / 3$ diastolic $\mathrm{BP})$ and $\mathrm{PP}(\mathrm{PP}=$ diastolic $\mathrm{BP}$ - diastolic $\mathrm{BP})$. Increases in PP indicate greater stress on arteries, which increases the risks of vessel wall damage and of developing atherosclerosis and thrombosis. ${ }^{29,30}$ Based on the results of the Framingham Heart Study, Franklin et al suggest that PP is a better predictor of increased risk of coronary heart disease than systolic or diastolic BP. ${ }^{31}$ Benetos et al observed that PP is also a significant and independent predictor for risk of myocardial infarction. ${ }^{32-34}$ In our study, participants' PP decreased significantly $(P=0.010)$, from $54.11 \pm 11.29 \mathrm{mmHg}$ at baseline to $43.33 \pm 6.44 \mathrm{mmHg}$ at the end of training. This implies that HIIT can improve PP, and thus may decrease cardiovascular risk.

The results of the PANSS showed statistically significant decreases in General Psychopathology Scale, Negative Scale, and Total scores. There were modest increases in the Positive Scale score, from $12.28 \pm 2.3$ at baseline to $12.33 \pm 2.0$ at the end of training, but this was not statistically significant. 
Table 3 Positive and Negative Syndrome Scale score data

\begin{tabular}{|c|c|c|c|c|c|}
\hline \multirow{2}{*}{$\begin{array}{l}\text { PANSS } \\
\text { Positive Scale }\end{array}$} & \multicolumn{2}{|c|}{ Items } & \multirow{2}{*}{$\begin{array}{l}\text { Baseline } \\
1.67 \pm 0.49\end{array}$} & \multirow{2}{*}{$\begin{array}{l}\text { End of training } \\
.72 \pm 0.46\end{array}$} & \multirow{2}{*}{$\begin{array}{l}\boldsymbol{P} \text {-value } \\
0.317\end{array}$} \\
\hline & $\mathrm{PI}$ & Delusions & & & \\
\hline & $\mathrm{P} 2$ & Conceptual disorganization & $2.28 \pm 0.57$ & $2.22 \pm 0.55$ & 0.317 \\
\hline & $\mathrm{P} 3$ & Hallucinations & $2.17 \pm 0.5 \mid$ & $2.11 \pm 0.47$ & 0.317 \\
\hline & P4 & Hyperactivity & $2.39 \pm 0.70$ & $2.56 \pm 0.70$ & 0.083 \\
\hline & P5 & Grandiosity & $|| 7 \pm 0.5 \mid$. & $1.22 \pm 0.55$ & 0.317 \\
\hline & P6 & Suspiciousness/persecution & $|.56 \pm 0.5|$ & $1.50 \pm 0.5 \mathrm{I}$ & 0.317 \\
\hline & P7 & Hostility & $1.06 \pm 0.24$ & $1.00 \pm 0.00$ & 0.317 \\
\hline & \multicolumn{2}{|c|}{ Total Positive Scale score } & $12.28 \pm 2.27$ & $12.33 \pm 2.00$ & 0.729 \\
\hline Negative Scale & NI & Blunted affect & $2.39 \pm 0.85$ & $2.28 \pm 0.83$ & 0.157 \\
\hline \multirow[t]{7}{*}{ score } & N2 & Emotional withdrawal & $1.94 \pm 0.54$ & $1.83 \pm 0.5 \mathrm{I}$ & 0.157 \\
\hline & N3 & Poor rapport & $2.28 \pm 0.46$ & $|.83 \pm 0.7|$ & $0.005^{* *}$ \\
\hline & N4 & Passive/apathetic social withdrawal & $2.78 \pm 0.73$ & $2.67 \pm 0.49$ & 0.527 \\
\hline & N5 & Difficulty in abstract thinking & $1.89 \pm 0.47$ & $1.78 \pm 0.43$ & 0.157 \\
\hline & N6 & Lack of spontaneity and flow of conversation & $|.56 \pm 0.5|$ & $1.22 \pm 0.43$ & $0.014^{*}$ \\
\hline & N7 & Stereotyped thinking & $\mid .44 \pm 0.5 \mathrm{I}$ & $1.39 \pm 0.50$ & 0.317 \\
\hline & \multicolumn{2}{|c|}{ Total Negative Scale score } & $14.28 \pm 2.16$ & $|3.00 \pm 1.7|$ & $0.000 * * *$ \\
\hline General & GI & Somatic concern & $2.39 \pm 0.78$ & $1.94 \pm 0.73$ & 0.054 \\
\hline Psychopathology & $\mathrm{G} 2$ & Anxiety & $1.83 \pm 0.79$ & $1.56 \pm 0.62$ & 0.096 \\
\hline \multirow[t]{15}{*}{ Scale score } & G3 & Guilt feelings & $3.11 \pm 1.28$ & $2.72 \pm 0.57$ & 0.083 \\
\hline & G4 & Tension & $20.6 \mathrm{I} \pm 10.24$ & $20.44 \pm 00.70$ & 0.334 \\
\hline & G5 & Mannerisms and posturing & $10.61 \pm 00.70$ & $10.67 \pm 00.59$ & 0.564 \\
\hline & G6 & Depression & $20.28 \pm 00.83$ & $20.06 \pm 00.64$ & $0.046^{*}$ \\
\hline & G7 & Motor retardation & $20.06 \pm 00.80$ & $10.67 \pm 00.69$ & $0.020^{*}$ \\
\hline & G8 & Uncooperativeness & $10.78 \pm 00.65$ & $10.56 \pm 00.62$ & $0.046^{*}$ \\
\hline & G9 & Unusual thought content & $10.89 \pm 00.47$ & $10.78 \pm 00.43$ & 0.157 \\
\hline & GI0 & Disorientation & $10.17 \pm 00.38$ & $10.11 \pm 00.32$ & 0.655 \\
\hline & GII & Poor attention & $20.00 \pm 00.69$ & $10.78 \pm 00.65$ & $0.046^{*}$ \\
\hline & $\mathrm{G} 12$ & Lack of judgment and insight & $10.67 \pm 00.49$ & $10.50 \pm 00.5 \mid$ & 0.083 \\
\hline & $\mathrm{G} 13$ & Disturbance of volition & $|0.44 \pm 00.5|$ & $10.22 \pm 00.43$ & $0.046^{*}$ \\
\hline & GI4 & Poor impulse control & $20.28 \pm 00.46$ & $20.22 \pm 00.43$ & 0.655 \\
\hline & GI5 & Preoccupation & $10.28 \pm 00.46$ & $10.06 \pm 00.24$ & $0.046^{*}$ \\
\hline & GI6 & Active social avoidance & $10.78 \pm 00.43$ & $|0.50 \pm 00.5|$ & $0.025^{*}$ \\
\hline & \multicolumn{2}{|c|}{ Total General Psychopathology Scale score } & $31.17 \pm 5.95$ & $270.78 \pm 30.57$ & $0.001 * * *$ \\
\hline \multicolumn{3}{|c|}{ PANSS Total Scale score } & $57.72 \pm 8.669$ & $53.11 \pm 5.77$ & $0.000 * * *$ \\
\hline
\end{tabular}

Notes: The data are reported as the mean \pm standard deviation. $* P<0.05 ; * * P<0.01 ; * * * P<0.001$.

Abbreviation: PANSS, Positive and Negative Syndrome Scale.

The results also indicate a major improvement in the poor rapport, lack of spontaneity, and flow of conversation subscales of the Negative Scale score. In the General Psychopathology Scale, improvement was seen in the depression, motor retardation, uncooperativeness, poor attention,

Table 4 Self-reported BDI and BAI scores at baseline and at end of training

\begin{tabular}{|c|c|c|c|c|c|}
\hline & \multicolumn{2}{|c|}{ Baseline } & \multicolumn{2}{|c|}{$\begin{array}{l}\text { End of } \\
\text { training }\end{array}$} & \multirow[t]{2}{*}{$\begin{array}{l}P \text {-value of } \\
\text { Friedman ANOVA }\end{array}$} \\
\hline & Mean & SD & Mean & SD & \\
\hline $\mathrm{BDI}$ & 19.56 & 15.3 & 15.89 & 14.3 & $P=0.000 * * *$ \\
\hline BAI & 13.67 & 13.8 & 10.06 & 11.2 & $P=0.003^{* *}$ \\
\hline
\end{tabular}

Notes: $* * P<0.01$; *** $P<0.001$.

Abbreviations: ANOVA, analysis of variance; BDI, Beck Depression Inventory; BAI, Beck Anxiety Inventory; SD, standard deviation. and active social avoidance subscales, compatible with the BDI result.

Mean BAI scores decreased from $13.67 \pm 13.83$ at baseline to $10.06 \pm 11.18$ at the end of training, and this was statistically significant $(P=0.003)$. In contrast, no statistically significant changes were noted in the PANSS subscales for somatic concern, anxiety, and tension. We hypothesize that this result is related to the fact that HIIT can induce muscle soreness, and this may have confounded the somatic symptoms subscale.

Our results are compatible with those of previous studies showing that exercise can improve negative symptoms, depression, and anxiety. ${ }^{2,26,35,36}$ To our knowledge, ours is the first study using a program of HIIT in patients with chronic schizophrenia. In this study, we clearly defined the duration, frequency, and intensity of the exercise program. 


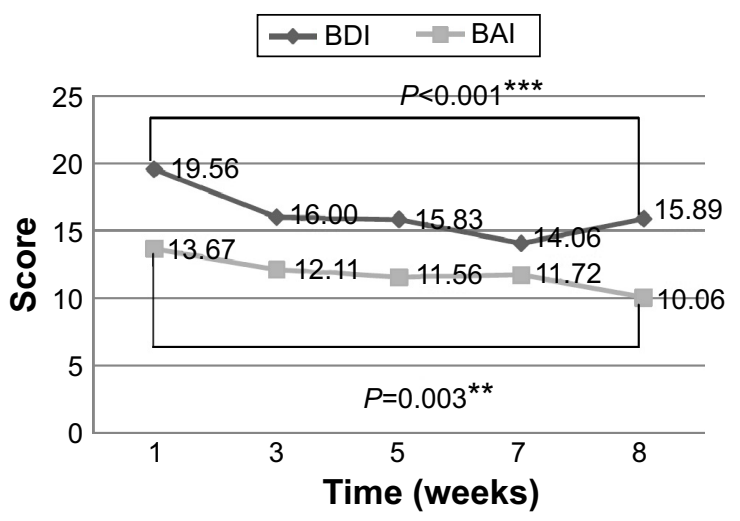

Figure $4 \mathrm{BDI}$ and $\mathrm{BAl}$ scores were recorded at regular intervals.

Notes: The BAI and BDI scores were recorded at the baseline (week I), then every 2 weeks, and at the end of the training program (week 8$)$. ( $* * P<0.01$; $* * * P<0.00 I)$. Abbreviations: BDI, Beck Depression Inventory; BAI, Beck Anxiety Inventory.

There were several limitations to our study, the main one being the lack of a control group. The primary reason we could not design this research as a randomized controlled trial is because the HIIT required participants' self-discipline and self-regulation to reach the high-intensity level required. The participants in this study were all highly motivated to join the HIIT group. To prevent selection bias, we design only the HIIT group. Second, there was only a single training group. Our present data cannot determine whether duration, frequency, or intensity of exercise is most beneficial for patients with schizophrenia. Third, the study had a small sample size, with only 18 patients completing the study. This is a reflection of the fact that most patients with schizophrenia cannot meet the criteria for HIIT and is also related to poor motivation due to negative symptoms. Our study also has selection bias, ie, there were 28 volunteers at the beginning of the study, but for patient safety, we only included 20 who were in relatively good physical condition and with relatively good motivation and exercise adherence. Only two participants voluntarily withdrew from the study (Figure 1).

\section{Conclusion}

This study demonstrates that a program of HIIT has positive effects on the mental and physical health of patients with chronic schizophrenia. After the training program, patients showed improved BW, BMI, PP, and resting HR, as well as improvements in negative symptoms, depression, and anxiety. Future studies could investigate duration, frequency, and intensity of exercise, to establish optimal work and rest schedules that are most beneficial for patients with schizophrenia.

\section{Disclosure}

The authors report no conflicts of interest in this work.

\section{References}

1. Rosenbaum S, Tiedemann A, Sherrington C, Curtis J, Ward PB. Physical activity interventions for people with mental illness: a systematic review and meta-analysis. J Clin Psychiatry. 2014;75(9):964-974.

2. Scheewe T, Backx F, Takken T, et al. Exercise therapy improves mental and physical health in schizophrenia: a randomised controlled trial. Acta Psychiatr Scand. 2013;127(6):464-473.

3. Vancampfort D, Probst M, De Hert M, et al. Neurobiological effects of physical exercise in schizophrenia: a systematic review. Disabil Rehabil. 2014;36(21):1749-1754.

4. Dishman RK. Advances in Exercise Adherence. Champaign, IL, USA: Human Kinetics Publishers; 1994.

5. Perri MG, Anton SD, Durning PE, et al. Adherence to exercise prescriptions: effects of prescribing moderate versus higher levels of intensity and frequency. Health Psychol. 2002;21(5):452.

6. Vancampfort D, Knapen J, Probst M, Scheewe T, Remans S, De Hert M. A systematic review of correlates of physical activity in patients with schizophrenia. Acta Psychiatr Scand. 2012;125(5):352-362.

7. Soundy A, Wampers M, Probst M, De Hert M, Stubbs B, Vancampfort D. Physical activity and sedentary behaviour in outpatients with schizophrenia: a systematic review and meta-analysis. Int J Ther Rehabil. 2013;20(12):588-596.

8. Soundy A, Stubbs B, Probst M, Hemmings L, Vancampfort D. Barriers to and facilitators of physical activity among persons with schizophrenia: a survey of physical therapists. Psychiatr Serv. 2014;65(5):693-696.

9. Stubbs B, Probst M, Soundy A, et al. Physiotherapists can help implement physical activity programmes in clinical practice. $\mathrm{Br} J$ Psychiatry. 2014;204(2):164.

10. Jacobs RA, Fluck D, Bonne TC, et al. Improvements in exercise performance with high-intensity interval training coincide with an increase in skeletal muscle mitochondrial content and function. $J \mathrm{Appl}$ Physiol. 2013;115(6):785-793.

11. McKay BR, Paterson DH, Kowalchuk JM. Effect of short-term highintensity interval training vs. continuous training on $\mathrm{O} 2$ uptake kinetics, muscle deoxygenation, and exercise performance. J Appl Physiol. 2009;107(1):128-138.

12. Tabata I, Nishimura K, Kouzaki M, et al. Effects of moderate-intensity endurance and high-intensity intermittent training on anaerobic capacity and $\mathrm{VO}_{2}$ max. Med Sci Sports Exerc. 1996;28(10):1327-1330.

13. Babraj JA, Vollaard NB, Keast C, Guppy FM, Cottrell G, Timmons JA. Extremely short duration high intensity interval training substantially improves insulin action in young healthy males. BMC Endocr Disord. 2009;9(1):3

14. Warburton DE, McKenzie DC, Haykowsky MJ, et al. Effectiveness of high-intensity interval training for the rehabilitation of patients with coronary artery disease. Am J Cardiol. 2005;95(9):1080-1084.

15. Perry CG, Heigenhauser GJ, Bonen A, Spriet LL. High-intensity aerobic interval training increases fat and carbohydrate metabolic capacities in human skeletal muscle. Appl Physiol Nutr Metab. 2008;33(6): $1112-1123$.

16. Klonizakis M, Moss J, Gilbert S, Broom D, Foster J, Tew GA. Low-volume high-intensity interval training rapidly improves cardiopulmonary function in postmenopausal women. Menopause. 2014;21(10): 1099-1105.

17. Roxburgh BH, Nolan PB, Weatherwax RM, Dalleck LC. Is moderate intensity exercise training combined with high intensity interval training more effective at improving cardiorespiratory fitness than moderate intensity exercise training alone? J Sports Sci Med. 2014;13(3): 702-707.

18. Bartlett JD, Close GL, MacLaren DP, Gregson W, Drust B, Morton JP. High-intensity interval running is perceived to be more enjoyable than moderate-intensity continuous exercise: implications for exercise adherence. J Sports Sci. 2011;29(6):547-553.

19. Hardcastle SJ, Ray H, Beale L, Hagger MS. Why sprint interval training is inappropriate for a largely sedentary population. Front Psychol. 2014; 5:1505.

20. Schoenfeld B, Dawes J. High-intensity interval training: applications for general fitness training. Strength Cond J. 2009;31(6):44-46. 
21. Lunt H, Draper N, Marshall HC, et al. High intensity interval training in a real world setting: a randomized controlled feasibility study in overweight inactive adults, measuring change in maximal oxygen uptake. PLoS One. 2014;9(1):e83256.

22. Abdel-Baki A, Brazzini-Poisson V, Marois F, Letendre É, Karelis AD. Effects of aerobic interval training on metabolic complications and cardiorespiratory fitness in young adults with psychotic disorders: a pilot study. Schizophr Res. 2013;149(1):112-115.

23. Heggelund J, Nilsberg GE, Hoff J, Morken G, Helgerud J. Effects of high aerobic intensity training in patients with schizophrenia - a controlled trial. Nord J Psychiatry. 2011;65(4):269-275.

24. Heggelund J, Kleppe KD, Morken G, Vedul-Kjelsås E. High aerobic intensity training and psychological states in patients with depression or schizophrenia. Front Psychiatry. 2014;5:148.

25. Herbsleb M, Mühlhaus T, Bär K-J. Differential cardiac effects of aerobic interval training versus moderate continuous training in a patient with schizophrenia: a case report. Front Psychiatry. 2014;5:119.

26. Biddle GF, Stuart. Exercise as an adjunct treatment for schizophrenia: a review of the literature. Journal of Mental Health. 1999;8(5): 441-457.

27. Stanton R, Happell B. A systematic review of the aerobic exercise program variables for people with schizophrenia. Curr Sport Med Rep. 2014;13(4):260-266.

28. James PA, Oparil S, Carter BL, et al. 2014 evidence-based guideline for the management of high blood pressure in adults: report from the panel members appointed to the Eighth Joint National Committee (JNC 8). JAMA. 2014;311(5):507-520.
29. Domanski M, Mitchell G, Pfeffer M, et al. Pulse pressure and cardiovascular disease-related mortality: follow-up study of the Multiple Risk Factor Intervention Trial (MRFIT). JAMA. 2002;287(20): 2677-2683.

30. Domanski M, Norman J, Wolz M, Mitchell G, Pfeffer M. Cardiovascular risk assessment using pulse pressure in the first national health and nutrition examination survey (NHANES I). Hypertension. 2001; 38(4):793-797.

31. Franklin SS, Khan SA, Wong ND, Larson MG, Levy D. Is pulse pressure useful in predicting risk for coronary heart disease? The Framingham Heart Study. Circulation. 1999;100(4):354-360.

32. Benetos A, Safar M, Rudnichi A, et al. Pulse pressure a predictor of long-term cardiovascular mortality in a French male population. Hypertension. 1997;30(6):1410-1415.

33. Benetos A, Rudnichi A, Safar M, Guize L. Pulse pressure and cardiovascular mortality in normotensive and hypertensive subjects. Hypertension. 1998;32(3):560-564.

34. Benetos A. Pulse pressure and cardiovascular risk. J Hypertens. 1999; 17(5):S21-S24.

35. Gorczynski P, Faulkner G. Exercise therapy for schizophrenia Cochrane Database Syst Rev. 2010;5:CD004412.

36. Acil A, Dogan S, Dogan O. The effects of physical exercises to mental state and quality of life in patients with schizophrenia. J Psychiatr Ment Health Nurs. 2008;15(10):808-815.
Neuropsychiatric Disease and Treatment

\section{Publish your work in this journal}

Neuropsychiatric Disease and Treatment is an international, peerreviewed journal of clinical therapeutics and pharmacology focusing on concise rapid reporting of clinical or pre-clinical studies on a range of neuropsychiatric and neurological disorders. This journal is indexed on PubMed Central, the 'PsycINFO' database and CAS,

\section{Dovepress}

and is the official journal of The International Neuropsychiatric Association (INA). The manuscript management system is completely online and includes a very quick and fair peer-review system, which is all easy to use. Visit http://www.dovepress.com/testimonials.php to read real quotes from published authors. 